\title{
Aggression towards the GP: can we profile the GP-victim? A cross-section survey among GPs
}

\author{
Vince Demeur, MD ${ }^{1}$, Sarah Devos, MD², Esther Jans, MD³, \\ Birgitte Schoenmakers, PhD, MD ${ }^{4 *}$
}

${ }^{1}$ Student Researcher, Department of Public Health and Primary Care, Academic Centre of General Practice, University of Leuven, Leuven, Belgium; ${ }^{2}$ Student Researcher, Department of Public Health and Primary Care, Academic Centre of General Practice, University of Leuven, Leuven, Belgium; ${ }^{3}$ Student Researcher, Department of Public Health and Primary Care, Academic Centre of General Practice, University of Leuven, Leuven, Belgium; ${ }^{4}$ Professor, Department of Public Health and Primary Care, Academic Centre of General Practice, University of Leuven, Leuven, Belgium

\begin{abstract}
Background: Aggression against GPs has increased in the past decade. Depending on experience, interpretation, and personality, the interpretation of aggressive patient behaviour will differ among doctors.
\end{abstract}

Aim: To investigate how often GPs experience aggression in a 1-year time span and what the relationship is between the GP's personality (based on the 'Big Five' personality traits) and the reporting of aggression. Secondly, to investigate how personality is related to feeling safe.

Design \& setting: Flemish (Belgian Federal State) GPs were questioned in a cross-sectional design by online survey. GPs were recruited and questioned in their professional environment.

Method: Outcome measures were the 'Big Five' personality traits ('reserved' versus 'outgoing', 'compassionate' versus 'challenging', 'efficient' versus 'careless', 'confident' versus 'nervous', and

*For correspondence: Birgitte. Schoenmakers@kuleuven.Be

Competing interests: The authors declare that no competing interests exist.

Received: 27 March 2018

Accepted: 29 March 2018

Published: 19 September 2018

(c) This article is Open Access: CC BY license (https://

creativecommons.org/licenses/ by/4.0/)

Author Keywords: Aggression, personality, general practitioner, patient

Copyright (C) 2018, The Authors; DOI:10.3399/

bjgpopen18X101604 'cautious' versus 'innovative', based on Cattel's 'Big Five' model of personality), the type of aggression, the reporting of aggression, and feeling safe.

Results: Both ( $n=247$ ) male and female doctors considered physical contact and verbal intimidation as aggression. Female doctors were more likely to consider sexual harassment as aggression. The majority of GPs were confronted with verbal aggression. More than half considered physical aggression as the most threatening. GPs with 'reserved' and 'careless' personality types were more likely to experience aggression. GPs with 'innovative', 'challenging', or 'confident' personality types were also at increased risk, but to a lesser extent than those with 'reserved' and 'careless' personalities. GPs with 'efficient' and 'innovative' personalities were more likely to report incidents. Male GPs and those with 'efficient' personalities felt safer. GPs with 'confident' and 'cautious' personalities were more likely to feel unsafe.

Conclusion: The results of this study might help future interventions and support strategies (designed to prevent aggressive incidents or help GPs cope with them) to target the vulnerable groups. Further research should therefore explore the results of these data in depth and on a larger sample size. 


\section{How this fits in}

Aggression from patients to doctors is increasing. Past research, profiling of the aggressor, led to interventions. By profiling the victim (victim personality and other features), interventions can be tailor-made and target the vulnerable professional.

\section{Introduction}

Aggression against GPs has been a known phenomenon for a long time, but the number of incidents seems to have increased in recent years. Recently, the murder of a GP in Belgium by a patient during a home visit brought attention to this issue again. ${ }^{1,2}$ Although there is a national aggression reporting system, not every doctor who is confronted with aggression will report this as an incident. Goldberg identifies four levels of aggression: verbal aggression, physical aggression, psychological aggression (threat and intimidation), and sexual harrassment. ${ }^{3}$ Depending on the GP's experience, interpretation, and personality, the attribution of an incident to one of these levels will differ.

A study in the Netherlands shows that $64 \%$ of GPs were confronted with verbal aggression in the last year. Compared with physician assistants, GPs report more incidents of threats, intimidation, and discrimination. Nevertheless, the majority (96\%) of GPs feels safe during work. This cross-sectional research also demonstrates that young and/or female GPs, GPs on out-of-hours duty, and GPs in urban or suburban areas experience more aggression. ${ }^{4}$

In Germany, researchers observed that more than half of the surveyed physicians had been confronted with a mild or moderate types of aggression, and more than one in 10 had experienced serious aggression. In this study, only $9 \%$ had never experienced any aggression during their professional career. Although most female doctors felt safe in their surgery, only one in three felt safe at home visits during out-of-hours duty. ${ }^{5}$ In a French study, physical or verbal aggression was reported by $56 \%$ of the GPs. The reporting of incidents was not related to the sex of the reporting victim. In most cases, aggression occured because the doctor refused to issue a prescription. ${ }^{6}$ Five Australian studies show that almost three-quarters of the surveyed physicians had dealt with aggression at during their career. ${ }^{7-11}$ In these studies, the premise that women are more likely to face aggression was not confirmed. However, women are confronted more often with sexually unacceptable behaviour. GPs with longer working days or fewer years of experience face more episodes of aggression. ${ }^{11}$ According to recent research, there is a lasting impact of aggression towards care professionals: a reduction of daily working hours, lower job satisfaction, and an intention to quit the job. ${ }^{12,13}$

Although many researchers focus on profiling the aggressor and describing the context of incidents, there is no consensus on outcome. Additionally, the research outcome seems to disagree with reality: the high prevalence of aggression incidents reported in research is not in accordance with the number of incidents reported in reality. It is not unthinkable that the experiencing and reporting of incidents is influenced by context and circumstances.

This study investigates how often a GPs face aggression, and what the relationship is between the personality of the GP and the type of aggressive incidents. It also investigates how the personality of the GP is related to the feeling of safety.

\section{Method}

\section{Population}

The target population consisted of all Flemish (Belgian Federal State) GPs. GPs were recruited through the local and regional professional registration network of active GPs. There were no exclusion criteria.

\section{Design}

A cross-sectional observational study was quantitatively carried out through an online survey. The survey was developed based on scientific literature and expert consultation. Questions were answered by a yes/no option, by a multiple choice option, or by free text fields. Five personality traits were measured using a 4-point Likert scale: 'reserved' versus 'outgoing', 'compassionate' versus 'challenging', 'efficient' versus 'careless', 'confident' versus 'nervous', and 'cautious' versus 
'innovative'. These personality traits were based on Cattel's 'Big Five' model of personality. ${ }^{14}$ This model was developed and refined over the past 2 decades and, in application, is an understandable and comprehensive way to categorise personality traits (Box 1).

The survey also contained demographic and practice characteristics of physicians, self-reported frequency of aggression, characteristics of aggressor, circumstances of aggression, measures taken to prevent aggression, and impact of aggression. In order to gain a better understanding of what GPs consider as aggression, participants were asked to complete each answer with a free-text comment.

The internet survey was sent early December 2016 to all Flemish GP networks. The network coordinators distributed the survey to the network members through a link on the website or by a printed flyer. In March 2017, a reminder was sent to the network coordinator and the link to the survey was announced in the newsletter of Domus Medica (a nonprofit syndical, training, and scientific family medicine organisation) and posted on the website of the ICHO (Interuniversitair Centrum voor Huisartsenopleiding, the Flemish nonprofit organisation of postgraduate training in family medicine). The data collection of the survey took place between 1 December 2016 and 2 April 2017.

\section{Outcome measures}

The outcomes of the study are the prevalence of aggression, the characteristics of the aggression, and the personality characteristics of the physician who experiences aggression or experiences feeling unsafe.

\section{Data analysis}

In order to work with a 95\% confidence interval $(\mathrm{Cl})$ and a 5\% error margin, a sample size of 369 responders was required to generate a power of 0.90 . This was calculated on the basis of 9157 licensed GPs and family doctors in training in Flanders in 2015, and the prevalence and distribution of aggression incidents. ${ }^{15}$ The results of the survey were exported from Google Forms to Excel, and univariate analyses were calculated using Excel (version 2016). The cut-off for 'frequently experiencing aggression' was set at 'monthly or more often'. The personality characteristics were described on a 4-point Likert-type scale. Responses 1 and 2 were considered as personality $X$; responses 3 and 4 as the opposite, personality Y. Multivariate regression analyses were carried out with the statistical program SAS (version 9.4), and the correlations between independent variables (sex, age, region, personality trait) and dependent variables (ever experienced aggression, declaration of incident, and feelings of safety) were calculated. The personality characteristics were interpreted as a continuous spectrum on a Likert scale, ranging from more personality $\mathrm{X}$ to more personality $\mathrm{Y}$.

\section{Results}

\section{Sample size and feature responders}

Of the 248 completed surveys, one was excluded because of a discrepancy between the age and number of years of experience. The results were based on a sample of 247 GPs. Given this sample size, the error margin was $6.15 \%$.

Box 1. Explanation of 'Big Five' personality traits

\begin{tabular}{|lcc|}
\hline Lower score & Personality trait & Higher score \\
\hline Practical, conventional, prefers routine & Openness & Curious, wide range of interests \\
\hline Impulsive, careless & Conscientiousness & Hardworking, dependable, organised \\
\hline Quiet, reserved, withdrawn & Extroversion & Outgoing, warm, seeks adventure \\
\hline Critical, uncooperative, suspicious & Agreeableness & Helpful, trusting, empathic \\
\hline Calm, secure & Neuroticism & Anxious, unhappy \\
\hline
\end{tabular}


Most responders were female (60.3\%). In addition, $47.4 \%$ were aged $<35$ years. More GPs operated in a rural area (58.7\%) than an urban area (41.3\%). Most participants $(52.6 \%)$ worked in a group practice (see Table 1).

There was an equal distribution of personality traits among the responders except for the 'nervous' trait: this personality was largely underrepresented (Table 2).

\section{Prevalence and context of aggression}

Both male and female doctors considered physical contact (gripping, striking, or slapping) and verbal intimidation as aggression. In addition, female doctors were more likely to consider sexual harassment or intimidation as aggression than male doctors: $81.9 \%$ of female responders considered this as aggression versus only $54.1 \%$ of male responders (Table 3 ).

Of all responders, 79.8\% experienced aggression in the last year. A considerable number (11.3\%) experienced aggression every month or more often. Only 5.3\% of the GPs reported never having been the victim of aggression. Of the responders, $89.8 \%$ had been confronted with verbal aggression, $21.1 \%$ with psychological aggression, $20.6 \%$ with physical aggression, and $7.7 \%$ with sexual aggression. However, $63.6 \%$ of GPs considered physical aggression as the most threatening form. While verbal aggression appeared the most common type of aggression, only $1.9 \%$ experienced this as the most threatening type (Table 3 ).

In $40.1 \%$ of the cases, the last incident of aggression took place during the consultation, in $22.7 \%$ during home visits, and in $18.6 \%$ by telephone. Only $6.5 \%$ of the incidents occurred in the waiting room. In more than half of the cases (55.1\%) the aggressor was known by the doctor. In $32.1 \%$ of the incidents, the aggressor had a known psychiatric history, and $11.7 \%$ of the aggressors were under influence of alcohol, drugs, or medication. Triggers of aggression were not meeting the

Table 1. Demographic features of the responders

\begin{tabular}{|c|c|c|c|c|}
\hline & & Male, n & Female, $n$ & Total, $n$ \\
\hline \multirow[t]{4}{*}{ Age, years } & $25-35$ & 24 & 93 & 117 \\
\hline & $36-45$ & 10 & 21 & 31 \\
\hline & $46-55$ & 24 & 24 & 48 \\
\hline & $>55$ & 40 & 11 & 51 \\
\hline \multirow[t]{7}{*}{ Experience, years } & $>40$ & 9 & 1 & 10 \\
\hline & $31-40$ & 32 & 7 & 39 \\
\hline & $21-30$ & 23 & 25 & 48 \\
\hline & $11-20$ & 7 & 16 & 23 \\
\hline & $6-10$ & 7 & 18 & 25 \\
\hline & $0-5$ & 12 & 40 & 52 \\
\hline & GP resident & 8 & 42 & 50 \\
\hline \multirow[t]{6}{*}{ Province } & Antwerp & 15 & 21 & 36 \\
\hline & Brussels & 0 & 2 & 2 \\
\hline & Limburg & 9 & 18 & 27 \\
\hline & East Flanders & 31 & 41 & 72 \\
\hline & Flemish Brabant & 25 & 48 & 73 \\
\hline & West Flanders & 18 & 19 & 37 \\
\hline \multirow[t]{2}{*}{ Location } & Rural & 60 & 85 & 145 \\
\hline & Urban & 38 & 64 & 102 \\
\hline \multirow[t]{3}{*}{ Practice } & Single-handed & 52 & 29 & 81 \\
\hline & Two-handed & 10 & 26 & 36 \\
\hline & Group & 36 & 94 & 130 \\
\hline Total & & 98 & 149 & 247 \\
\hline
\end{tabular}


Table 2. Personality traits of the responders, $n(N=247)$

\begin{tabular}{|c|c|c|c|c|c|}
\hline Likert scale & 1 & 2 & 3 & 4 & \\
\hline Reserved & 17 & 94 & 95 & 41 & Outgoing \\
\hline Compassionate & 21 & 125 & 93 & 8 & Challenging \\
\hline Efficient & 71 & 98 & 68 & 10 & Careless \\
\hline Confident & 93 & 123 & 31 & 0 & Nervous \\
\hline Cautious & 20 & 96 & 108 & 23 & Innovative \\
\hline
\end{tabular}

patient's demands (72.5\%), disagreement with the proposed treatment $(41.7 \%)$, and the exceeding of scheduled waiting times (30.8\%), as shown in Table 4.

Although most responders had experienced aggression, most of them were not severely mentally or physically injured. However, $31.2 \%$ of physicians reported an emotional impact, $5.7 \%$ material damage (infrastructure), and $2.8 \%$ physical damage as a consequence. Two GPs experienced temporary medical leave from work. Only $12.6 \%$ of the responders reported the incident. Of those who never reported the incident, $47.7 \%$ considered doing so in the future. Finally, $88.7 \%$ of GPs generally felt safe (Table 5).

\section{Multivariate regression analysis}

The multivariate regression analysis did not find a significant link between age, sex, or personality and 'ever experienced aggression'. The same was true for the analysis of age, sex, practice, and location as independent variables and 'ever experienced aggression' as a dependent variable. A more 'efficient' personality was significantly more likely to report the incident than a more 'careless' personality (odds ratio [OR] $0.578,95 \% \mathrm{Cl}=0.358$ to 0.931 ). A more 'cautious' personality was less likely to report than an 'innovative' personality (Table 6).

In addition, two multivariate analyses were performed with 'feeling of safety' as a dependent variable and age, sex, personality characteristics, practice type, and location as independent variables. These analyses showed a highly significant result for sex (with a significance level of $P<0.01$ ). Men significantly felt safer than women (OR $0.155,95 \% \mathrm{Cl}=0.038$ to 0.637 versus $\mathrm{OR} 0.162,95 \% \mathrm{Cl}=$ 0.043 to 0.615 ). A more 'efficient' personality was positively associated with feeling safe (OR 0.576, $95 \% \mathrm{Cl}=0.334$ to 0.992 ). 'Confident' personalities were significantly more likely to feel unsafe than

Table 3. Types of aggression, as experienced by GPs. Frequency of GPs experiencing aggression type versus frequency of considering it the most threatening type of agression

Type of aggression

\begin{tabular}{ccc} 
Male, $\boldsymbol{n}$ & Female, $\boldsymbol{n}$ & Total, $\boldsymbol{n}$ \\
\hline 25 & 62 & 87 \\
72 & 125 & 197 \\
\hline 79 & 134 & 213 \\
\hline 43 & 66 & 109 \\
\hline 36 & 62 & 98 \\
\hline 83 & 135 & 218 \\
\hline 53 & 122 & 175 \\
\hline 5 & 8 & 13 \\
\hline & & \\
\hline $22 / 76$ & $29 / 81$ & \\
\hline $85 / 3$ & $137 / 2$ & \\
\hline $14 / 12$ & $38 / 10$ & \\
\hline $2 / 5$ & $17 / 53$ & \\
\hline $2 / 2$ & $5 / 3$ & \\
\hline
\end{tabular}


Table 4. Context of aggression incident

\begin{tabular}{|c|c|c|}
\hline & Context & Total, $\mathbf{n}$ \\
\hline \multirow[t]{6}{*}{ Situation } & Consultation & 99 \\
\hline & Home visit & 56 \\
\hline & Out-of-hours & 16 \\
\hline & Public & 2 \\
\hline & Telephone & 46 \\
\hline & Other & 28 \\
\hline \multirow[t]{7}{*}{ Characteristics of aggressor } & Known patient & 136 \\
\hline & Unknown patient & 59 \\
\hline & Under influence of drugs, alcohol, or medication & 29 \\
\hline & Psychiatric history & 79 \\
\hline & Criminal history & 17 \\
\hline & Repeat aggressor & 9 \\
\hline & Other & 29 \\
\hline \multirow[t]{8}{*}{ Cause } & Money & 13 \\
\hline & Waiting time & 76 \\
\hline & Discussion about fee & 10 \\
\hline & Reaction to bad news & 9 \\
\hline & Disagrement with diagnosis & 33 \\
\hline & Disagrement with treatment & 103 \\
\hline & Not meeting demands & 179 \\
\hline & Other & 37 \\
\hline
\end{tabular}

'nervous' personalities (OR 2.460,95\% Cl $=1.232$ to 4.910$)$; likewise, 'cautious' personalities were significantly more likely to feel unsafe than 'innovative' personalities (OR $2.444,95 \% \mathrm{Cl}=1.252$ to 4.769), as shown in Table 6.

\section{Discussion}

\section{Summary}

This is the first study to explore the relationship between aggression and victim characteristics. Most participating GPs had already been confronted with aggression during their career. Of the responders, $79.8 \%$ reported an incident in the last year, and more than one in 10 experienced aggression monthly. The analysis of the personality characteristics showed that GPs with a rather 'reserved' or 'careless' personality type were more likely to face aggression. GPs with 'innovative',

Table 5. Impact of aggressive incident and frequency of reporting

\begin{tabular}{lccc} 
& Male, $\boldsymbol{n}$ & Female, $\boldsymbol{n}$ & Total, $\boldsymbol{n}$ \\
\hline Physical injury & 3 & 4 & 7 \\
\hline Material damage & 8 & 6 & 14 \\
\hline Emotional damage & 25 & 52 & 77 \\
\hline Medical leave & 2 & 0 & 2 \\
\hline Other & 3 & 8 & 11 \\
\hline None & 65 & 86 & 151 \\
\hline Reporting of incident & 12 & 19 & 31
\end{tabular}


Table 6. Relationship between GPs' characteristics and reporting an aggressive incident, and relationship between GPs' characteristics and feeling unsafe

Characteristics of GP versus reporting incident

Odds ratio

$95 \% \mathrm{Cl}$

\begin{tabular}{lll}
\hline Older age & 0.978 & 0.947 to 1.009 \\
\hline Male & 1.503 & 0.606 to 3.730 \\
\hline Reserved & 1.151 & 0.682 to 1.942 \\
\hline Compassionate & 1.111 & 0.588 to 2.100 \\
\hline Efficient & 0.578 & 0.358 to 0.931 \\
\hline Confident & 1.212 & 0.666 to 2.208 \\
\hline Cautious & 1.784 & 1.014 to 3.138 \\
\hline Characteristics versus feeling unsafe & & 0.968 to 1.050 \\
\hline Older age & 1.008 & 0.038 to 0.637 \\
\hline Male & 0.155 & 0.366 to 1.155 \\
\hline Reserved & 0.650 & 0.540 to 2.088 \\
\hline Compassionate & 1.062 & 0.334 to 0.992 \\
\hline Efficient & 0.576 & 1.232 to 4.910 \\
\hline Confident & 2.460 & 1.252 to 4.769 \\
\hline Cautious & 2.444 &
\end{tabular}

'challenging', or 'confident' personality types were at increased risk, but to a lesser extent than the first category.

\section{Strengths and limitations}

First, the participants were mainly young doctors and women, which might have caused a selection bias. It can be assumed that these doctors participated because they frequently experienced aggression. Second, the survey only addressed aggression incidents during the last 12 months. Third, the response rate of this survey is too low to unconditionally extrapolate the results; based on the sample size of $247 \mathrm{GPs}$, the error margin is $6.15 \%$. On the other hand, the results of the multivariate analyses were based on meaningful, reliable, and valid models.

\section{Comparison with existing literature}

The results of incidence and prevalence of this study were comparable to those of other studies. ${ }^{4-7}$

Female doctors were more often confronted with aggression than males. In addition, younger doctors and urban practitioners seemed to be victims more often than older colleagues or rural practitioners. The latter may be related to the higher prevalence of crime in urban areas. ${ }^{16} \mathrm{~A}$ Dutch national baseline measure of aggressive incidents in general practice published in 2014 also confirmed these groups as most vulnerable to aggression. ${ }^{4}$ Although an earlier Australian study ${ }^{10}$ observed that female and younger GPs, and those working in socioeconomically disadvantaged areas, experienced more aggression, a recent Australian study ${ }^{11}$ did not confirm this. A French study did not observe a significant difference in prevalence of aggression by sex. ${ }^{6}$

Female GPs also reported a lower sense of safety during their work than their male colleagues. A German study confirmed this observation but the difference with their male colleagues was smaller than in the present study. ${ }^{5}$ This difference might be explained by the more frail physiognomy of women as compared to men. ${ }^{17}$ In general, female doctors will be less able to defend themselves in case of a physically aggressive attack than male doctors. Women may, in this case, benefit from training in self-defense and verbal assertiveness.

Men and women also respond in a different way to stressful situations. Female doctors are more likely to suffer emotional damage as a result of aggression than their male colleagues. ${ }^{17}$ In this study, one in three women reported emotional damage compared to one in four men. Women could therefore benefit more than men from interventions to prevent aggression. 
Verbal aggression was by far the most common type of aggression in daily practice. ${ }^{4-11}$ Verbal aggression creates an uncomfortable work environment and can affect the psychological wellbeing of the recipient. Communication training in role-playing or in real life situations could improve the interaction with patients and probably reduce triggers leading to aggressive incidents.

About one in five GPs in this study had experienced psychological or physical aggression, which is consistent with other findings. ${ }^{5-6,18}$ As in other studies, only half of the male doctors experienced sexual harassment, compared to more than four in five of all female doctors. ${ }^{5,11}$ Sexual harassment remains a widespread problem in society. Media campaigns aiming to increase public awareness can reduce the incidents of sexual harassment.

Aggression occurred most often during the consultation, though one in five doctors experienced aggression during a home visit. Of course, most patient contacts take place in the doctors' surgery. ${ }^{5,19}$ Besides this, it is assumed that patients feel more at ease at home, which lowers the risk of discussion leading to aggression. Home visits remain a valuable way of caring for patients. Visiting patients under the supervision of a guard is not commonly accepted or desirable, but might be considered in certain circumstances (for example, unsafe neighborhoods, unknown patients, patients with addiction issues, or night shifts).

In this study, the relationship between aggression by a patient and the characteristics of the GP was also examined. This arose from the observation that prevalence of aggression strongly varies among studies. In addition, although the definition of aggression is well described, the perception or interpretation of aggressive behaviour seems to depend on the victim (it is the eye of the beholder).

GPs with a 'reserved' personality type are perhaps more likely than 'outgoing' personalities to interpret patients' behaviour as aggressive; the survey was based on the subjective interpretation of aggression and not on an objectively defined definition of aggressive behaviour. In addition, it is possible that the physician with a 'careless' personality type adheres less to the time schedule, meaning longer waiting times for patients. A long waiting time is identified as a trigger of aggressive patient behaviour. Finally, it is surprising that the doctors with 'confident' personality types experienced more aggression than their 'nervous' counterparts. This can possibly be explained by the very low number of doctors describing themselves as 'nervous'.

'Efficient' type personalities appeared to feel safer. Those with 'confident' and 'cautious' type personalities were more likely to report feeling unsafe. Although surprising that 'confident' doctors reported feeling more unsafe than their 'nervous' counterparts, it might be that they are more aware of the real risk of an aggressive incident, and that this makes them feel more unsafe. In addition, 'confident' doctors are less likely to report an aggressive incident and are therefore also less likely to be supported after an incident, which may contribute to feeling unsafe. Remarkably, physicians with 'efficient' type personalities who experienced aggression were more likely to report aggression incidents than their 'cautious' colleagues. This might suggest that reporting incidents increases the feelings of safety.

\section{Implications for research}

Aggression towards GPs is remarkably common. In the last year, no fewer than eight out of 10 GPs experienced aggression, mostly verbal aggression. The aggressor is usually a known patient. GPs are not used to reporting aggressive incidents so the real prevalence will be higher. ${ }^{15}$

More than one in $10 \mathrm{GPs}$ do not feel safe during their professional hours. In particular female GPs, and GPs with 'confident' personality types and 'cautious' personality types feel significantly less safe. GPs with a more 'efficient' personality type generally feel safer.

The results of this study might help future interventions and support strategies, designed to prevent aggressive incidents or help GPs cope with them, target the vulnerable groups. Since personality traits or features such as sex are unchangeable, interventions should focus on the most efficient and suitable coping strategy. Further research should therefore explore the results of these data in depth and on a larger sample size.

Funding

No funding was received for this study. 
Ethical approval

The study was approved by the Medical Ethical Board of the University Hospitals of Leuven in May 2017 (reference number: MP14149).

\section{Provenance}

Freely submitted; externally peer reviewed.

\section{Acknowledgments}

The authors would like to express their gratitude to the GPs who participated in this research.

\section{References}

1. Domus Medica. [Posthumous tribute to Patrik Roelandt] PRaag: postuum eerbetoon aan Patrik Roelandt. 2016. http://www.domusmedica.be/documentatie/nieuwskijker/6622-praag-postuum-eerbetoon-aan-patrikroelandt.html (accessed 7 Aug 2018).

2. Nationale Raad Orde der Artsen. [National Contact Point for aggression, Document 153006, Journal 153] Nationaal meldpunt voor agressie tegen artsen, Document 153006, Journal 153. Brussels: Nationale Raad Orde der Artsen. 2016.

3. Goldberg LR. The development of markers for the Big-Five factor structure. Psychological Assessment 1992; 4(1): 26-42. doi: 10.1037/1040-3590.4.1.26

4. Van Der Kemp S, De Ruig L, Sticht Soc Fonds Huisartsenzorg. [Working safe in general practice: survey addressing the character and extent of aggression towards GPs] Veilig werken in de huisartsenzorg? Een nulmeting van de omvang en aard van agressie in de huisartsenzorg. 2014. https://www.ssfh.nl/fileadmin/ Files/documenten/Actueel/2015/Eindrapport_Veilig_werken_in_de_huisartsenzorg.pdf (accessed 31 Aug 2018).

5. Vorderwülbecke F, Feistle M, Mehring $M$, et al. Aggression and violence against primary care physicians - a nationwide questionnaire survey. Dtsch Arztebl Int 2015; 112(10): 159-165. doi: 10.3238/arztebl.2015.0159

6. Clinet ML, Vaysse B, Gignon M, et al. Violences subies par les médecins généralistes exerçant en libéral: sous-déclaration des agressions ou des atteintes aux biens [Violence undergone by the general practitioners: Under-reporting of the attacks or of the infringements to their properties] (in French). Presse Med 2015; 44 (11): e321-329. doi: 10.1016/j.lpm.2015.01.018

7. Forrest $L$, Parker $R$, Hegarty $K$, et al. Patient initiated aggression and violence in Australian general practice. Aust Fam Physician 2010; 39(5): 323-326.

8. Tolhurst H, Baker L, Murray G, et al. Rural general practitioner experience of work-related violence in Australia. Aust J Rural Health 2003; 11(5): 231-236.

9. Alexander C, Fraser J. Occupational violence in an Australian healthcare setting: implications for managers. $J$ Healthc Manag 2004; 49(6): 377-390. doi: 10.1097/00115514-200411000-00007

10. Magin PJ, Adams J, Sibbritt DW, et al. Experiences of occupational violence in Australian urban general practice: a cross-sectional study of GPs. Med J Aust 2005; 183(7): 352-356.

11. Koritsas S, Coles J, Boyle $M$, et al. Prevalence and predictors of occupational violence and aggression towards GPs: a cross-sectional study. Br J Gen Pract 2007; 57(545): 967-970. doi: 10.3399/ 096016407782604848

12. Hills $D$, Joyce CM. Workplace aggression in clinical medical practice: associations with job satisfaction, life satisfaction and self-rated health. Med J Aust 2014; 201(9): 535-540. doi: 10.5694/mja13.00152

13. Hills DJ. Associations between Australian clinical medical practitioner exposure to workplace aggression and workforce participation intentions. Aust Health Rev 2016; 40(1): 36-42. doi: 10.1071/AH14246

14. Goldberg LR. An alternative 'description of personality': the Big-Five factor structure. J Pers Soc Psychol 1990; 59(6): 1216-1229. doi: 10.1037/0022-3514.59.6.1216

15. Decoster C, Somer A, De Geest A, et al. [Year statistics concerning practitioners of health care professions in Belgium] Jaarstatistieken met betrekking tot beoefenaars van gezondheidszorgberoepen in België. Brussels: Belgian Federal Public Service Health, Food Chain Safety and Environment. 2015.

16. Hardyns $W$, van de Velde $M$, Pauwels $L$, et al. [High prevalence criminality, victimhood and urbanity in Belgium: a criminographic analysis] Veelvoorkomende criminaliteit, slachtofferschap en stedelijkheid in België: een criminografische analyse. In: Pauwels L, De Keulenaer S, Deltenre S, eds. [Criminographic developments: from victim-survey tot penitentary statistics] Criminografische ontwikkelingen: van (victim)survey tot penitentiare statistiek. Antwerp: Maklu. 2010. 27-60.

17. Graham K, Wells S. The two worlds of aggression for men and women. Sex Roles 2001; 45(9-10): 595-622. doi: 10.1023/A:1014811624944

18. Hobbs FD, Keane UM. Aggression against doctors: a review. J R Soc Med 1996; 89(2): 69-72. doi: 10.1177/ 014107689608900203

19. Colson W. [Increase of 56000 urgent patient encounters with GP's in 2015] 56000 meer dringende raadplegingen bij huisarts in 2015. 2016. http://www.artsenkrant.com/actueel/56-000-meer-dringenderaadplegingen-bij-huisarts-in-2015/article-normal-20085.html (accessed 31 Aug 2018). 